\title{
SURVIVAL AFTER TRANSFUSION OF Rh-POSITIVE ERYTHROCYTES PREVIOUSLY INCUBATED WITH Rh ANTIBODY
}

\author{
BY \\ P. L. MOLLISON \\ From the Medical Research Council Blood Transfusion \\ Research Unit, Postgraduate Medical School of London \\ AND \\ J. C. S. PATERSON \\ Department of Medicine, Postgraduate Medical School of
}

(RECEIVED FOR PUBLICATION, DECEMBER 15, 1948)

It has been concluded that if blood is taken from a patient with acquired haemolytic anaemia and transfused to a normal recipient the erythrocytes survive normally (Loutit and Mollison, 1946). This finding is not an easy one to understand since the erythrocytes at the moment of transfusion are coated with antibody and give a positive direct Coombs test, and it might be thought that if the degree of sensitization were adequate only the addition of complement was necessary to complete their lysis. In discussing this finding it was suggested that immune body might be washed off the erythrocytes when they were put into the circulation of a normal patient. It was further suggested that there was probably some other substance, "co-haemolysin," present in the plasma of patients with acquired haemolytic anaemia in addition to the antibody giving the positive Coombs reaction. Some such theory was necessary to explain the findings in the case of a patient who recovered spontaneously from acquired haemolytic anaemia and to longer destroyed transfused erythrocytes rapidly although her own red cells continued to give a positive direct Coombs test.

Owren (1947) made some observations which were a little at variance with those reported above. He took erythrocytes from a patient with acquired haemolytic anaemia and transfused them to a normal-recipient. Approximately 50 per cent of the erythrocytes disappeared from the recipient's circulation within three days, and during this period it could be demonstrated that the surviving donor cells gave a positive direct Coombs test. After three days the surviving cells no longer gave a positive test and were eliminated at the normal rate only. This observation suggested that the coating of erythrocytes with antibody did in fact lead to their rapid destruction, and that the idea that antibody could simply be washed off the erythrocytes, leaving them undamaged, might be wrong.

It seemed desirable to find out first whether erythrocytes coated with antibody, or " sensitized erythrocytes" as they may conveniently be called, lose their coat of antibody when circulating in the plasma of a normal recipient, or whether they retain it ; and secondly to make further observations on the effect of this coating on the survival of erythrocytes.

A further incentive to perform experiments came from the observation that an infant might have a positive direct Coombs test without developing any signs of increased blood destruction (Pickles, 1947 ; Mollison and Cutbush, 1949).

\section{Methods}

Donor Blood.-Concentrated erythrocyte suspensions prepared from blood stored for three to four days in disodium-citrate glucose were used. Varying amounts of serum containing $R h$ antibody of the "albumin agglutinin " or "blocking" type were added (see the Table, and note that in one case a serum containing saline agglutinins was also added). The mixtures were incubated in a water-bath at $37^{\circ} \mathrm{C}$. for one hour. A sample of the mixture was then withdrawn and the direct Coombs test was performed. The mixture was then transfused to a patient. In one preliminary experiment (Case 1) blood was mixed with a very small amount of weak $R h$ antibody. Since 
TABLE

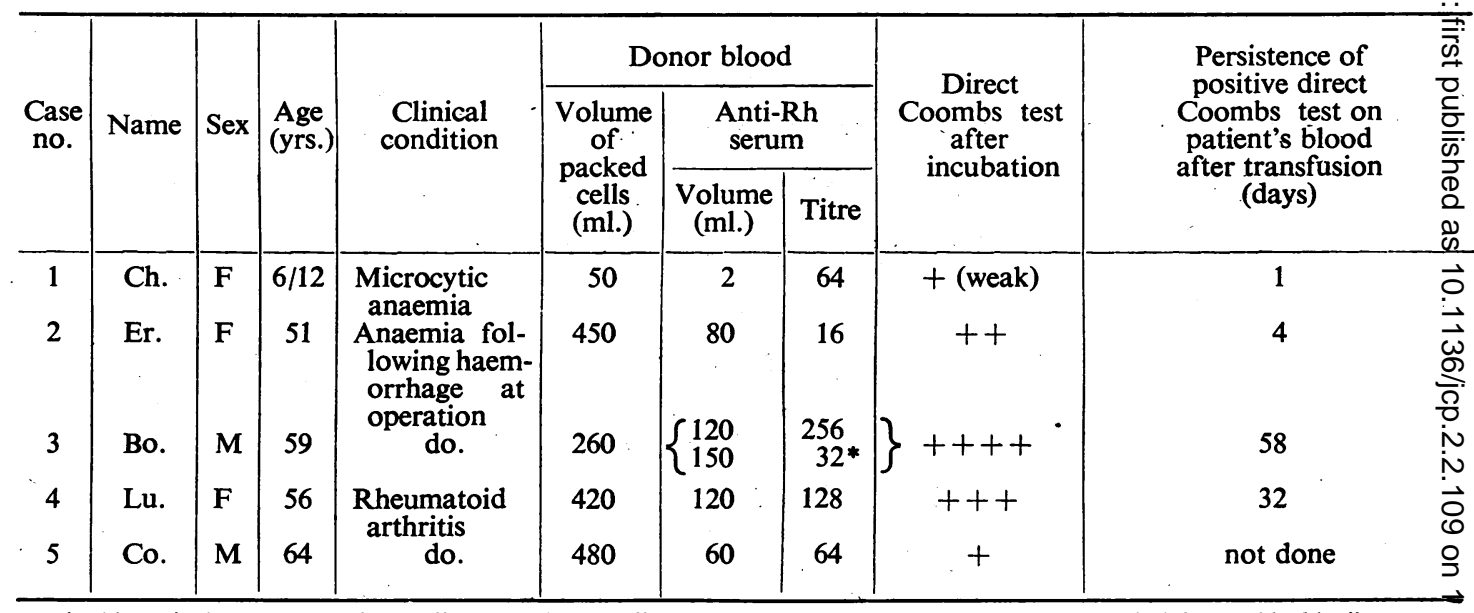

- This anti-Rh sefum contained saline agglutinins; all the other sera used were of the albumin-agglutinin or "blocking" type.

there were no signs at all of increased blood destruction when this mixture was transfused, larger proportions of anti-Rh serum were used in the succeeding cases.

Recipients.-Survival tests were carried out on five patients, all of whom required transfusion for the relief of chronic anaemia. Brief details are given in the Table. All the recipients were Rh-positive.

Survival of transfused erythrocytes was determined by a modification (Dacie and Mollison, 1943) of Ashby's (1919) method.

Direct Coombs Test.-The test described by Coombs, Mourant, and Race (1945) was used; the precise technique used in these experiments was that described by Mollison and Cutbush (1949).

\section{Results}

Survival of Sensitized Erythrocytes.-The survival of sensitized erythrocytes in two patients (Cases 2 and 3 ) is plotted in Fig. 1. The percentage survival at ten days in both cases is a little lower than normal, although the remainder of the curve is strictly normal. The apparent initial departure from linearity in these cases is too small to be taken as definite evidence of an increased rate of destruction. Nevertheless it is a suggestive finding in view of similar small deviations from normality in the cases of Loutit and Mollison. The question is discussed below.

The survival of sensitized erythrocytes in two patients with rheumatoid arthritis (Cases 4 and 5) was appreciably shorter, 50 per cent of transfused erythrocytes being eliminated in about 22 days. In view of the results in Cases 2 and 3 it was felt that this reduced survival might be due to some abnormality of the recipient rather than to any effect of $\mathrm{Rh}$ antibody. on the donor erythro-

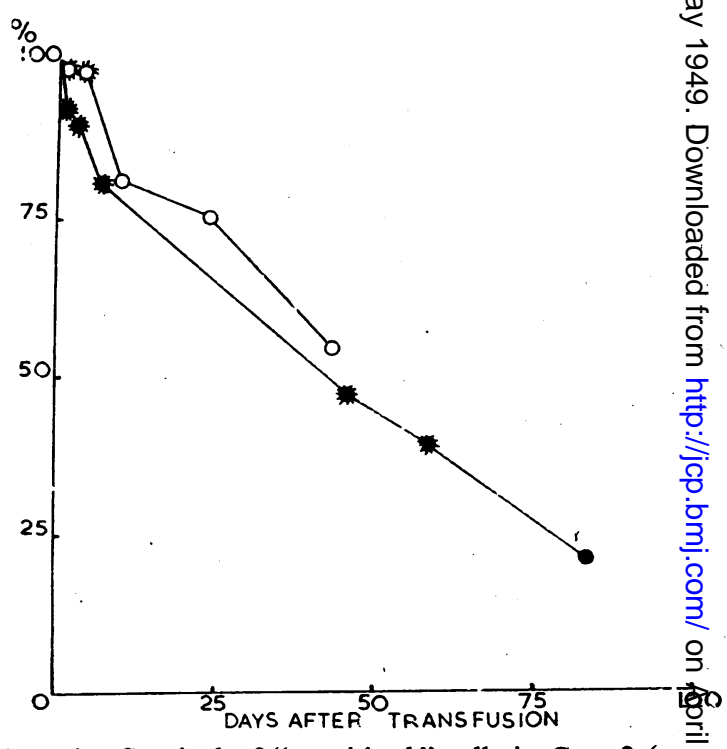

FIG. 1. Survival of " sensitized" cells in Case 2 (open circles) and Case 3 (solid circles). Starred circtes show direct Coombs test positive.

cytes. This supposition was tested by retransfusiug the two recipients at a later date with normal blood. In Case 4 elimination of the norngal erythrocytes was just as rapid as that of the sensitized erythrocytes (see Fig. 2). In Case 5 normigl erythrocytes survived normally. However, in this patient there had been some clinical improvem git since the time when the transfusion of sensitized erythrocytes had been given. In view of the resuffts in the other patient with rheumatoid arthritis, it is possible that normal survival on the second ocsa- 
sion is rather to be ascribed to an alteration in the disease process than to any difference between normal and sensitized erythrocytes, especially since the sensitized cells transfused to this patient were only weakly sensitized.

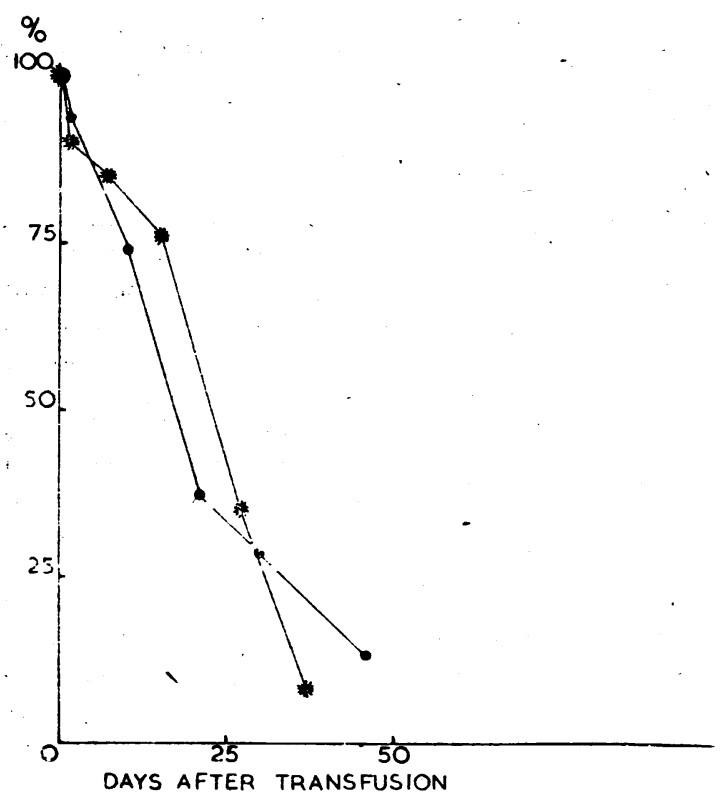

FIG. 2.-Survival in Case 4 of "sensitized" and normal cells transfused on different occasions. Starred circles show direct Coombs test positive (after transfusion of sensitized cells).

Persistence of a Positive Direct Coombs Test.In Cases 1, 2, 3, and 4 a direct Coombs test was performed on the recipient's blood at intervals after transfusion. In Case 1 , in which the donor cells were only weakly sensitized, the direct Coombs test was positive on the day after transfusion but not thereafter; in Case 2, in which the donor cells were moderately. sensitized before transfusion, the direct Coombs test was positive - four days after transfusion but negative at ten days. However, in Case 3, in which the donor cells were very strongly sensitized, the direct Coombs test was still positive 58 days after transfusion. In Case 4 the direct Coombs test was positive for 32 days after transfusion.

In cases where the recipient's blood became "Coombs positive" after transfusion, it was noted that all the erythrocytes, and not just a fraction, corresponding to the proportion of donor cells present, were agglutinated.

This general sensitization of the recipient's erythrocytes was not aceompanied by any signs of an increased rate of blood destruction. In the patient (Case 3) in whom the direct Coombs test remained positive for 58 days after transfusion, some special examinations were made on the 46th day after transfusion. The haemoglobin was $9.5 \mathrm{~g}$. compared with $9.6 \mathrm{~g}$. immediately after transfusion, the reticulocyte count was 0.6 per cent, and the plasma bilirubin concentration less than $0.5 \mathrm{mg} . / 100 \mathrm{ml}$.

A few simple experiments were undertaken to discover how rapidly $R h$ antibody was transferred from sensitized Rh-positive cells to unsensitized ones.

\section{Experiments in Vitro}

I. Sensitized Rh-positive Cells Incubated with $R$ h-positive and Rh-negative Cells Respectively

Suspensions of erythrocytes in saline were prepared from $(a)$ the blood of an infant with haemolytic disease, (b) normal Rh-positive blood, (c) normal Rhnegative blood.

In each case the erythrocytes were washed three times in saline and then made up to a suspension of approximately 50 per cent in saline. Mixtures of these suspensions were made as below and incubated for one hour at $37^{\circ} \mathrm{C}$.

(1) $0.4 \mathrm{ml}$. $a$ alone.

(2) $0.5 \mathrm{ml} . a+0.5 \mathrm{ml} . b$.

(3) $0.5 \mathrm{ml} . a+0.5 \mathrm{ml} . c$.

After incubation samples of (1), (2), and (3) were each tested against an anti-globulin serum. The results were as follows:

(1) The sensitized cells alone showed a very strong positive reaction.

(2) The mixture of sensitized cells with the normal Rh-positive cells showed slower reaction, but agglutination was complete eventually.

(3) The mixture of sensitized cells with Rh-negative cells gave the appearance of a mixture of well agglutinated and unagglutinated cells.

To confirm the impression gained from these macroscopic tests, microscopic tests were done as follows.

Small volumes of (1), (2), and (3) were mixed with equal volumes of anti-globulin serum in tubes and centrifuged. Then $10 \mathrm{ml}$. saline were added to each tube and mixed gently; the mixtures were spun once more and again gently mixed. A drop of each mixture was now examined in a counting chamber.

With the sensitized cells alone (1) there were only three to five free cells per broad column of the Bürker ruling (i.e., agglutination was virtually complete). With the mixture of sensitized and normal Rh-positive cells (2) there were only ten cells per broad column (i.e., agglutination virtually complete, but not quite so strong). With the mixture of sensitized cells and $R h$-negative cells (3) there were very numerous free cells and, many small clumps. From this experiment it was concluded that all the normal Rh-positive cells had become coated with antibody during incubation with sensitized Rh-positive cells. 


\section{Sensitized Rh-positive Cells Incubated in Excess Normal Plasma}

$1 \mathrm{ml}$. of normal Rh-positive blood was incubated with $0.1 \mathrm{ml}$. serum containing $\mathrm{Rh}$ antibody (albumin titre 128, saline titre nil); the cells were then washed and made up to a 20 per cent suspension in saline. $0.1 \mathrm{ml}$. of these sensitized cells was incubated for one hour with $2 \mathrm{ml}$. normal plasma. At the end of this time the cells were tested in parallel with sensitized cells that had not been mixed with excess plasma to discover whether any appreciable amount of antibody had come off the cells during incubation. This latter possibility was also tested by performing an indirect Coombs test on the plasma after incubation.

It was found that there was no detectable diminution in the strength of the direct Coombs test after incubating the cells in excess plasma and that no free antibody was detected in the plasma. From this it was concluded that $R h$ antibody does not readily wash off red cells to which it has become attached, unless other Rh-positive erythrocytes are present.

\section{Discussion}

If the results of Loutit and Mollison (1946) are examined closely two things will be noted. Firstly, with regard to the patients with acquired haemolytic anaemia from whom blood was taken for transfusion to normal recipients, it will be observed that in none of the four cases was haemolysis more than moderately active at the time of the experiment. Thus one patient had made a clinical recovery, two patients (previously severely affected) had had their spleens removed, and the fourth case was mild. Nevertheless in two cases (those in which blood destruction had been very rapid before splenectomy), there was in fact some evidence that a small proportion of the cells was destroyed more rapidly than normal after transfusion to normal recipients ; the exact figures were 79 per cent and 84 per cent survival respectively one week after transfusion, compared with an expected figure of about 93 per cent. Loutit and Mollison drew attention to this finding, but laid more stress on the normal survival of the main mass of the transfused cells.

In the present two patients (Cases 2 and 3) in whom the bulk of the transfused erythrocytes also survived normally, the percentage survivals, seven to ten days after transfusion, were 81 per cent and 82 per cent respectively. Thus it seems quite likely that, although the bulk of the sensitized erythrocytes survived normally, there may have been a fraction which was destroyed more rapidly. If this is so, the substantial initial destruction observed by Owren may have been merely an exaggeration of the same effect. Two factors in his case may have contributed to this result. Firstly, it may be that the haemolytic process in his patient was f more active at the time of transfusion than in the cases of Loutit and Mollison. Secondly, Owrên transfused a larger volume of blood-namely, $\frac{f}{2}$ litres. The effect which this may have had demands separate consideration.

The tests in vitro demonstrate that $\mathrm{Rh}$ antibod is readily transferred from sensitized $R h$-positive cells to unsensitized Rh-positive cells. This implies that within a very short period of transfusiog probably less than an hour, the amount of antibody originally attached to the donor erythrocytes is shared among all the circulating erythrocytes. If only some $500 \mathrm{ml}$. of blood are transfused, thys must reduce the amount of antibody on each ceft to about $1 / 6$ th or less of the amount initially attached to the donor cells, even when the recipief has a reduced erythrocyte volume. In Owren's case, due to the larger amount of sensitized blood transfused, the reduction in the amount of antic body on each of the donor erythrocytes must hate been less.

It may have been a coincidence that in Owren case the direct Coombs test, performed on the recipient's cells, became negative at the same time as the rapid destruction ceased. The time for which the test remains positive depends to a lar extent on the sensitivity of the Coombs' reagen In any case, our observations demonstrate that the direct Coombs test can remain positive over quite long periods without leading to any increase in the rate of erythrocyte destruction.

\section{Summary}

1. Rh-positive erythrocytes were incubated vitro with serum containing $R h$ antibody of the albumin-agglutinin type, and then transfused anaemic patients. The erythrocytes were found to retain their coat of antibody, as demonstrated by the direct Coombs test, for long periods aftor transfusion.

2. When Rh-positive erythrocytes, sensitized vitro, are transfused to an $\mathrm{Rh}$-positive recipients the $\mathbf{R h}$ antibody becomes redistributed amongs: the erythrocytes of both the donor and recipiente. Hence the amount of antibody attached to the donor erythrocytes must be rapidly reduced.

3. Whereas the bulk of the sensitized erythr $\AA$ cytes survive normally after transfusion, it is possible that a small proportion may be destroyed more rapidly. Further experiments are needed $\mathbb{1 0}_{0}$ decide this point.

4. These findings can be interpreted in two ways. (a) The coating of erythrocytes by $\mathrm{Rh}$ antibody 
determines the haemolysis of erythrocytes in vivo only when a certain minimal quantity of antibody is exceeded ; $(b)$ the antibody detected by the antiglobulin test does not by itself, or in co-operation with any normal plasma constituent, cause haemolysis.

5. Whatever the interpretation of these findings, it is clear that the finding that erythrocytes give a positive direct Coombs test cannot by itself be taken as evidence that the erythrocytes are being destroyed at an abnormal rate.
We should like to thank Professor Ian Aird and Dr. E. G. L. Bywaters for allowing us to make investigations upon patients under their care, and Dr. J. V. Dacie for many helpful suggestions during the preparation of this paper.

\section{REFERENCES}

Ashby, W. (1919). J. exp. Med., 29, 267.
Coombs, R. R. A., Mourant, A. E., and Race, R. R. (1945). Brit. J. exp. Path., 26, 255.

Dacie, J. V., and Mollison, P. L. (1943). Lancet, 1, 550.

Loutit, J. F., and Mollison, P. L. (1946). J. Path. Bact., 58, 711.

Mollison, P. L., and Cuthush, Marie (1949). Brit. med. J., 1, 123.

Owren, P. A. (1947). Tidsskr. norske Laegeforen., 67, 665.

Pickles, M. M. (1947). Dissertation for the degree of D.M., Oxford. 